\title{
Research on Cultural Communication in Chinese International Education from the Perspective of Communication
}

\author{
Nian Qing \\ Shaanxi University of Chinese Medicine, Shaanxi Xi'an 712046, China
}

Keywords: Communication; Perspective; Chinese; International Education; Cultural Communication

\begin{abstract}
With the continuous development of Chinese education, our culture has been widely disseminated in all countries of the world. The main purpose of Chinese international education is to spread our country's culture. Due to the differences between the cultures of countries in the world, the spread of Chinese culture in other countries is more difficult. Therefore, how to effectively disseminate Chinese culture is a question that we need to ponder. This paper analyzes the current situation of cultural communication in Chinese international education and studies the application and dissemination methods of the media in Chinese international education.
\end{abstract}

With the development of economy, the cultural exchange activities between countries all over the world are increasing. The cultural communication in Chinese international education is of great significance for the dissemination of Chinese culture. With the improvement of China's international status, all countries in the world have actively paid attention to China's cultural studies in order to achieve a smooth "dialogue" with China in various fields. At the same time, China has also actively promoted the spread of Chinese culture in the world and has provided a consensus platform for deeper cooperation in various fields. However, at present, there are still some problems in the cultural dissemination of Chinese international education, which is one of the main approaches to the spread of Chinese culture. How to effectively solve these problems and use Chinese language international education as a carrier to enhance the effectiveness of Chinese cultural communication is a question that we need to ponder.

\section{Related Concepts Analysis}

\subsection{Explaining Chinese International Education}

With the development of economy, cultural exchanges between countries around the world have become increasingly close. Under this background, Chinese international education has gradually developed. Its purpose is to promote Chinese language while spreading Chinese culture. Chinese international education refers to teaching Chinese to native speakers of other languages, fully demonstrating China's international status and effectively promoting the spread of Chinese culture ${ }^{[1]}$. Through the platform of Chinese international education, not only can the personnel of other 
countries systematically learn Chinese and Chinese culture, but also promote the exchange between our country's culture and other countries' cultures and promote the dissemination and development of our country's culture.

\subsection{Communication and Cultural Communication}

Communication studies mainly study how humans regularly arrange numbers and symbols together so that they can communicate with each other. People began to study communication science long ago, but in the 20th century to the 1940s, communication studies formally developed into disciplines. At this stage, experts and scholars from various countries have conducted studies on communication science and have had a tremendous impact on cultural communication. With the development of network technology, the significance of communication science in the new era has received more attention from people. In recent years, communication science has made great progress in our country, and the theory system of communication science has also gradually improved. Its connection with our daily life is also increasingly close. Under normal circumstances, cultural communication activities are propagated from culturally prosperous regions to regions that are relatively lacking in culture, thereby promoting cultural development. Cultural communication can increase the exchange of various cultures and promote the spread of Chinese culture. It is of great significance for promoting the development of our country's culture and enhancing our international status.

\section{Status Quo of Cultural Communication in Chinese International Education}

\subsection{Diversification of the Media}

With the development of science and technology, the types of cultural media are also constantly increasing. These media are of great significance in promoting the spread of culture in Chinese international education and promoting the development of Chinese culture ${ }^{[2]}$. With the development of network technology and the development of the media in the direction of diversification, it has the following advantages: First, the mode of transmission of the media has changed, which has effectively promoted the initiative of cultural communication. Secondly, due to the increase in the types of media people can choose different methods to spread culture, which makes cultural communication more convenient. Thirdly, cultural communication develops toward the direction of cultural integration. People can use communication media to spread language culture, sound culture, and image culture, and increase the speed of cultural communication. Finally, the spread of culture is no longer constrained by time and space, which has enhanced the effect of cultural dissemination in China and promoted the development of our country's culture. With the development of network technology, the media must move toward diversification. We should seize the opportunity to promote cultural communication.

\subsection{Rich and Diverse Modes of Communication}

With the development of science and technology and economy, the mode of cultural transmission is also moving toward diversification, which plays an important role in promoting the spread of culture in Chinese international education. For a long time before, we all used paper textbooks to spread culture. This method is autonomous and systematic ${ }^{[3]}$. Chinese teaching and broadcasting is also an effective method of transmission. This mode of transmission is not constrained by time and space. With the development of network technology, we began to use the Internet to spread our culture. By using the Internet, we can quickly spread our culture and enhance the effectiveness of 
cultural communication. Although the diversification of cultural transmission methods can promote cultural communication in Chinese international education, we also need to continuously develop new modes of communication with the development of science and technology and society, improve the efficiency and effectiveness of cultural communication, and promote the development of Chinese culture.

\subsection{Close communication between Media and Audience}

The study found that the media has a close relationship with the audience. Although culture originates from life, it will also provide services for life and gain development in life, thereby realizing cultural values. This is also true of the cultural communication in Chinese international education. Only by ensuring that cultural communication is similar to the audience's life can we achieve the goal of cultural communication while satisfying the needs of the audience, so as to reflect the value of our culture. The media can meet the needs of the audience, and the Chinese culture is also disseminated with the audience.

\section{Application of Communication Media in Chinese International Education}

\subsection{Print Media}

In the 1950s, China began to compile teaching materials for foreigners. Until now, there are thousands of teaching materials and supplementary materials for foreigners in China. These teaching materials and supplementary materials can be used by international learners of different ages and levels to provide help, which also includes the "Spoken Chinese Oral" ${ }^{[4]}$. In terms of newspapers, although China has compiled newspaper reading materials, it has not set up learning newspapers for international Chinese learners. In short, China's current use of a wider range of print media is a paper textbook, newspapers, magazines, etc. are less used.

\subsection{Electronic media}

In the spread of culture, electronic media will not be constrained by time and area. Therefore, compared with print media, electronic media have certain advantages in communication. In 1962, China had already set up a "Chinese Lecture" column in Japanese radio and achieved good results. Afterward, many "Chinese Language Learning" programs were broadcast in various media. The "Daily Chinese" section has become an important column of Chinese language international education in broadcast media. The study found that electronic media plays an important role in Chinese international education.

\subsection{Network Media}

The network media has comprehensive features. At this stage, there are many Chinese international education websites in China, such as the "Confucius Institute Official Website" of the Confucius Institute ${ }^{[5]}$. With the development of network technology, there has emerged a network of media, which will break the constraints of time and geographical aspects of traditional teaching and cultural communication methods, making Chinese international education and cultural communication more personalized. Our country has invested a lot of funds and energy in building a number of Chinese language international education websites, which have a positive effect on the development of Chinese international education. 


\subsection{Mobile Media}

With the development of science and technology and economy, more and more people have chosen to use smart phones to communicate and learn. Therefore, the role of mobile media has also gradually received people's attention. China has developed related APPs to promote some Chinese international education information for users, making Chinese education and cultural communication more flexible and lively, and effectively promoting the dissemination and development of Chinese culture.

\section{Exploration of the Transmission Mode of Chinese International Education Media}

\subsection{The Way of Media Transmission}

The media has three physical characteristics: communication symbols, communication carriers and modes of transmission. This is also the characteristics of the media itself, and it is also an important basis for media to carry out cultural communication activities. No matter what kind of information needs to be represented by symbols, these symbols need to be transported using material carriers. Because the media technologies that transmit information symbols are different, the means of transmission are different. Propagation methods have their own advantages and disadvantages, and the scope of application of different transmission methods is also not the same.

As the transmission of symbols and propagation vectors will directly influence the mode of media transmission, we need to understand the communication symbols and propagation carriers ${ }^{[6]}$. Propagation symbols refer to the symbols used in media transmission information, including texts, sounds, etc. The way of different symbols transmit information is also different. The carrier refers to the technical means of carrying and transmitting information and the terminal facilities for receiving information. For example, the carrier of newspapers is printing technology and paper; the carrier of television is electronic imaging technology, electronic transmission technology, and television sets. Communication carriers will directly affect the speed of cultural transmission, the scope of transmission, and the cost of transmission.

The mode of communication is an activity mode that connects the media to the audience. The modes of transmission mainly include the following types: First, depending on the form in which the information is displayed on the terminal device, it can be divided into plane propagation mode, linear propagation mode, and synchronous propagation mode. Second, according to the needs of information, human senses can be divided into visual communication, auditory communication, etc. Finally, communication methods based on communication methods and audiences can be divided into single communication, interactive communication, and so on.

These transmission methods are used in Chinese international education and communication activities. For example, teachers of Confucius Institutes use language symbols to spread Chinese culture in teaching activities. Face-to-face language teaching can enable students to experience Chinese culture through visual senses, auditory senses, and language senses, effectively improving learning efficiency and effectiveness ${ }^{[7]}$. However, synchronous communication has a higher time and geographical requirements, and communicators and learners must communicate at the same time. At the same time, since students can only learn Chinese based on the sequence of their lectures, they cannot choose their own learning styles, and the oral medium cannot retain information for a long time. Only students in the classroom can receive information provided by teachers. Therefore, our country uses a variety of media in the international teaching of Chinese, and we will study the mode of dissemination of concentrated media. 


\subsection{Scientific Use of Paper Textbooks Media Communication Culture}

The paper teaching materials use text and pictures as communication symbols, and use paper as a carrier to convey the Chinese language knowledge to the audience in a written manner through complicated production and transportation. Therefore, the paper teaching materials belong to the plane transmission and delayed transmission mode.

Paper teaching media features: First, selectivity. In simple terms, the audience can choose to read content, can freely control reading speed and reading time. Second, limited and systematic ${ }^{[8]}$. In simple terms, it is the systematicness and limitedness of the content of paper teaching materials. These characteristics have resulted in the use of paper teaching materials as a widely used medium of Chinese international education and as an important medium for disseminating Chinese culture.

However, plane transmission and delayed transmission are also unfavorable for the development of paper textbook media. To attract a large audience and enhance the effect of cultural communication, we must first develop and use multimedia-assisted instructional resources corresponding to teaching materials to enhance the use of teaching materials. Secondly, in-depth study of Chinese culture and teaching of Chinese as a foreign language, and selection of simple Chinese teaching methods to enhance teaching effectiveness. Finally, we continuously improve the published textbooks, and at the same time we must compile new Chinese textbooks and combine electronic textbooks with paper teaching materials. In this way, the rationality of the teaching materials can be guaranteed.

\subsection{Rational Use of Broadcast Media to Promote Chinese Culture}

The Chinese language teaching broadcast is a transmission mode in which sound is used as a transmission symbol and an infinite radio wave is used as a transmission carrier. An audience can use a radio to receive electric waves. Such a transmission method has features such as auditory propagation and linear propagation.

At this stage, China's international broadcasting stations have covered more than 200 countries and regions in the world and used more than 40 languages for broadcasting. The coverage of such broadcasting methods is the most extensive. In addition, through Chinese-language teaching broadcasters, broadcasters can build a good learning atmosphere for the audience to enhance their Chinese listening and speaking ability.

However, there are also some shortcomings in this mode of dissemination. Therefore, when using broadcast media for Chinese language teaching and cultural communication, the following points need to be noted: First, compile appropriate teaching materials for broadcasting Chinese language teaching programs to preserve broadcast content so that the audience can learn at any time and

consolidate Chinese knowledge ${ }^{[9]}$. Second, upload audio resources for broadcasting Chinese language teaching programs to the Internet so that audiences can download or order on-demand to reduce the negative impact of time on Chinese language teaching and cultural dissemination. Finally, compile and introduce China's stories, customs, news, social and other cultural broadcast programs, so that the audience can understand our culture.

\subsection{Attach Importance to Media Communication to Promote the Spread of Chinese Culture}

Television broadcast symbols are sound and video, which are transmitted to television receivers through the carrier of electromagnetic waves and displayed on the television screen. Such transmission methods have features such as audio-visual transmission and linear transmission. Television transmission is a combination of audiovisual and audiovisual communication. It will stimulate the audience's hearing and vision. The dissemination effect of this mode of transmission is 
better than that of broadcasting ${ }^{[10]}$. Chinese language teaching programs, through various communication occasions and TV teaching, enable audiences to directly experience Chinese culture and effectively improve the effectiveness of Chinese teaching and the effects of cultural communication. However, there are still some shortcomings in this mode of transmission, that is, poor autonomy and cannot be saved. In addition, due to the fact that television sets cannot be carried and TV program production costs are high, these are important factors that affect the development of TV Chinese teaching programs.

With the development of network technology, the Internet can spread the symbols of text, pictures, sounds, etc. through digital technology. At the same time, it can also be preserved. It also gives the audience a certain degree of autonomy and selectivity. The receiving terminal is also more diversified. We can use desktop computers, laptops, mobile phones, e-readers, etc. to receive information through the Internet. Due to the strong compatibility of these transmission symbols, the fast-optical transmission speed, and the diversity of receiving terminals, the Internet communication method can break through the constraints of time and area, and has the features of global communication, audio-visual compatibility, and synchronous and asynchronous features. This mode of transmission is incomparable to other transmission methods. Through the Internet, we can achieve functions such as distance Chinese teaching, online Chinese teaching, and sharing of Chinese language teaching resources. Therefore, we need to invest more funds and energy in Internet transmission methods to enhance cultural transmission speed.

\section{Conclusion}

In short, due to the cultural differences in various countries, the cultural communication in Chinese international education will encounter many problems, which will affect the effect of cultural communication. With the development of science and technology, in order to enhance the effect of cultural communication in Chinese international education, we need to make full use of the positive role of various media to achieve effective cultural dissemination in Chinese international education.

\section{References}

[1] Kai Yu. Research on the Teaching of Geographical Names Culture in Chinese International Education [D]. Yunnan University, 2016.

[2] Xiaohuan Zhou. Cross-Cultural Non-Verbal Communication Research for Chinese International Education [D]. Liaoning Normal University, 2016.

[3] Tianzi Wucai. Ten Strategies for Promoting Chinese International Communication [J]. Modern Chinese (Academic Edition), 2016(10):142-144.

[4] Liman Zhang. Chinese Culture Communication from the Perspective of Audience [J]. Today Media, 2017(5):60-61.

[5] Xiurong Lou. The Characteristics of Chinese Names and Words in the Perspective of International Education [J]. Journal of Shenyang Normal University (Social Sciences Edition), 2017, 41(1): 120-123.

[6] Wei Yao. A Comparative Study of Current Chinese and Korean Characters from the Perspective of Chinese International Communication [J]. Journal of Liaoning Education Administration, 2017, 34(3):87-91.

[7] Yu Zhu. Research on International Students' Chinese Cultural Word Acquisition from the Perspective of Communication Culture [D]. Anhui University, 2017.

[8] Rongjia Ye. Analysis of Chinese International Education Audience Based on Communication Theory [J]. Journalism Research Review, 2017, 8(12): 270-271.

[9] Yingying Li. Research on the Strategy of Communication of Filial Piety in Teaching Chinese as a Foreign Language in the Perspective of Comparison between China and the West [D]. Qufu Normal University, 2016.

[10] Jing Ren, Ye Tian. Research on the Cultural Communication Strategies of Chinese Students in Chinese Language Teaching [J]. Popular Literature, 2016(22):229-230. 